\title{
BMJ Open Temporal trends in severe maternal and neonatal trauma during childbirth: a population-based observational study
}

\author{
Qi Wen, ${ }^{1,2}$ Giulia M Muraca, ${ }^{3,4,5}$ Joseph Ting, ${ }^{6}$ Sarah Coad, ${ }^{3,4}$ Kenneth I Lim, ${ }^{3,4}$ \\ Sarka Lisonkova ${ }^{3,4,5}$
}

To cite: Wen Q, Muraca GM, Ting J, et al. Temporal trends in severe maternal and neonatal trauma during childbirth: a population-based observational study. BMJ Open 2018;8:e20578. doi:10.1136/ bmjopen-2017-020578

- Prepublication history and additional material for this paper are available online. To view these files, please visit the journal online (http://dx.doi. org/10.1136/bmjopen-2017020578).

Received 15 November 2017

Revised 8 January 2018

Accepted 31 January 2018

Check for updates

${ }^{1} \mathrm{BC}$ Children's Hospital Research Institute, Children's Hospital, Vancouver, Canada

${ }^{2}$ Department of Statistics and Actuarial Science, Simon Fraser University, Burnaby, Canada ${ }^{3}$ Department of Obstetrics and Gynaecology, University of British Columbia, Vancouver, Canada

${ }^{4}$ Children's and Women's Hospital and Health Centre of British Columbia, Vancouver, Canada

${ }^{5}$ School of Population and Public Health, University of British Columbia, Vancouver, Canada ${ }^{6}$ Department of Pediatrics, University of British Columbia and the Children's and Women's Hospital and Health Centre of British Columbia, Vancouver, Canada

Correspondence to

Dr. Sarka Lisonkova slisonkova@cfri.ca

\section{ABSTRACT}

Objective Instrumental vaginal delivery is associated with birth trauma to infant and obstetric trauma to mother. As caesarean delivery rates increased during the past decades, the rate of instrumental vaginal delivery declined. We examined concomitant temporal changes in the rates of severe birth trauma and maternal obstetric trauma. Design A retrospective observational study. Settings and participants All hospital singleton live births in Washington State, USA, 2004-2013, excluding breech delivery. Severe birth trauma (brain, nerve injury, fractures and other severe birth trauma) and obstetric trauma (third/fourth degree perineal lacerations, cervical/high vaginal lacerations) were identified from hospitalisation data. Pregnancy and delivery characteristics were obtained from birth certificates. Temporal trends were assessed by the Cochran-Armitage test. Logistic regression was used to obtain adjusted ORs (AORs) and 95\% Cl.

Results 0verall, 732818 live births were included. The rate of severe birth trauma declined from 5.3 in 2004 to 4.5 per 1000 live births in $2013(\mathrm{P}<0.001)$. The decline was observed only in spontaneous vaginal delivery, the rates of fractures and other severe birth trauma declined by $5 \%$ and $4 \%$ per year, respectively (AOR: 0.95 , $95 \% \mathrm{Cl} 0.94$ to 0.97 and AOR: $0.96,95 \% \mathrm{Cl} 0.93$ to 0.99 ; respectively). The rate of third/fourth degree lacerations declined in spontaneous vaginal delivery from $3.5 \%$ to 2.3\% (AOR: $0.95 ; 95 \% \mathrm{Cl} 0.94$ to 0.95 ) and in vacuum delivery from $17.3 \%$ to $14.5 \%$ (AOR: $0.97,95 \% \mathrm{Cl} 0.96$ to 0.98). Among women with forceps delivery, these rates declined from $29.8 \%$ to $23.4 \%$ (AOR: $0.98,95 \% \mathrm{Cl} 0.96$ to 1.00).

Conclusion While the rates of fractures and other birth trauma declined among infants delivered by spontaneous vaginal delivery, the rate of birth trauma remained unchanged in instrumental vaginal delivery and caesarean delivery. Among mothers, the rates of severe perineal lacerations declined, except for women with forceps delivery.

\section{INTRODUCTION}

Birth trauma refers to an injury sustained by the fetus during the process of labour and delivery, usually due to difficult vaginal birth with a need for obstetric manipulation of the fetus by forceps or vacuum (instrumental

\section{Strengths and limitations of this study}

Large, population-based data with detailed information on maternal and pregnancy risk factors.

- Consistent use of International Classification of Diseases, 9th revision, Clinical Modification codes to identify birth trauma during the study period.

- Lack of statistical power to detect temporal trends for very rare specific types of trauma.

- Lack of detailed clinical information on severity of some types of birth trauma.

- Non-differential errors in coding that may result in underestimation of temporal trends.

vaginal delivery). ${ }^{12}$ While some degree of trauma to the fetus during delivery is relatively common, severe birth trauma is rare..$^{2-5}$ Such birth trauma, for example, intracranial haemorrhage, however, can result in intrapartum stillbirth, neonatal death or functional impairment. ${ }^{1}$ The reported incidence of severe birth trauma in industrialised countries varies from 1.5 to 2.9 per 1000 live births, ${ }^{2-6}$ depending on the definition and study population. Mode of delivery is strongly associated with trauma to the fetus. Infants born by forceps and vacuum delivery have an approximately fourfold and threefold higher rates of birth trauma, respectively, as compared with those born by spontaneous vaginal delivery. ${ }^{4}$ Birth trauma can occur during caesarean delivery; however, the incidence rates are approximately $60 \%$ lower as compared with vaginal delivery. ${ }^{4}$

Mode of delivery is also associated with obstetric trauma to the mother, including third and fourth degree perineal lacerations, and cervical and high vaginal lacerations. Similarly to birth trauma, the rates of obstetric trauma vary, depending on definition and study population from $2 \%$ to $19 \% .^{7-9}$ While some studies in the USA show a significant decline in perineal lacerations over time, ${ }^{10}$ others from Denmark and Sweden 
report a temporal increase. ${ }^{11}{ }^{12}$ Short-term sequelae of obstetric trauma include perineal pain, ${ }^{13}$ painful sexual intercourse ${ }^{14}$ defaecatory dysfunction and urinary and faecal incontinence. ${ }^{1516}$ The long-term consequences of obstetric trauma, which manifest 10-20 years after childbirth, include pelvic floor disorders such as pelvic organ prolapse, urinary and faecal incontinence. ${ }^{17-21}$

Rates of caesarean delivery increased substantially in the industrialised countries during the past decades, ${ }^{22-25}$ while rates of instrumental vaginal delivery declined. In the USA, for example, caesarean delivery rate increased from $22.9 \%$ in 2000 to $32.9 \%$ in 2009 , and then declined slightly to $32.2 \%$ in 2014 . Over the same period, rate of forceps declined from $2.1 \%$ in 2000 to $0.6 \%$ in 2014 and rate of vacuum delivery declined from $4.8 \%$ to $2.6 \%{ }^{23}$ In Canada, rate of caesarean delivery increased from $25.8 \%$ in $2003 / 2004$ to $28.0 \%$ in $2010 / 2011,{ }^{24}$ while instrumental vaginal delivery declined from $12.0 \%$ of singleton births in 2004 to $10.7 \%$ in $2012 .{ }^{25}$ Since instrumental vaginal delivery is a strong risk factor for severe birth trauma and obstetric trauma, we hypothesised that the rates of severe birth trauma and obstetric trauma also declined over time.

Our objective was to characterise temporal trends in rate of severe birth trauma, including brain injury, fractures, nerve injury and other injury to tissue and organs, and to examine these trends by mode of delivery. The second objective was to examine temporal trends in the rates of obstetric trauma among women with spontaneous vaginal delivery, forceps and vacuum delivery.

\section{METHODS}

\section{Study population}

We included all singleton live births to mothers from 15 years to 60 years of age in Washington State, USA from 2004 to 2013. Excluded were women who were not residents of Washington State, births at $<20$ weeks' and $>44$ weeks' gestation, births occurring outside hospital and breech deliveries. We used data from the Birth Events Record Database (BERD), which included information abstracted from live birth certificates. These data were linked to the Comprehensive Discharge Abstract Database (CHARS), which included all hospitalisations in Washington State with up to nine diagnostic and procedure codes related to each hospitalisation episode. The BERD database provided information on maternal characteristics (maternal age, race, education, marital status, body mass index (BMI), chronic hypertension, diabetes mellitus, obstetric history and so on), and pregnancy, labour and delivery characteristics (gestational diabetes, hypertension in pregnancy, gestational age at delivery, mode of delivery, prolonged labour and so on).

\section{Outcomes definition}

Severe birth trauma was identified from the CHARS using diagnoses coded by the International Classification of Diseases, 9th revision, Clinical Modification (ICD-9-CM) (online supplementary appendix table 1). Severe birth trauma was classified as follows: (1) brain injury (subdural and cerebral haemorrhage and injuries to scalp); (2) fractures (fracture of clavicle and other injuries to skeleton); (3) nerve injury (injury to spine and spinal cord, facial nerve injury, injury to brachial plexus, other cranial and peripheral nerve injuries); and (4) other severe birth trauma (other specified birth trauma, eg, injury to the internal organs). A composite outcome 'any severe birth trauma' was defined as one or more injuries described above. Severe maternal obstetric injury was identified from hospital delivery records using ICD-9-CM codes and categorised as follows: (1) severe perineal lacerations (third and fourth degree perineal tears and anal sphincter injury) and (2) cervical or high vaginal lacerations (online supplementary appendix table 1 ).

\section{Mode of delivery}

Mode of delivery was categorised as spontaneous vaginal delivery, forceps delivery, vacuum delivery, primary caesarean delivery with labour, repeat caesarean delivery with labour, primary caesarean delivery without labour and repeat caesarean delivery without labour. Delivery where both instruments were used were included in forceps delivery category, while failed forceps and failed vacuum delivery were included in caesarean delivery group. Due to low numbers in caesarean delivery categories and congruent trends between primary and repeat caesarean delivery with labour, we combined the latter two categories into one. Neonatal death was defined as death within the first 28 days after birth, and neonatal mortality was compared between infants with and without birth trauma.

\section{Data analysis}

The Cochran-Armitage test was used to assess statistical significance of temporal trends. We assessed the temporal trend in the rates of each mode of delivery and the rates of severe birth trauma (per 1000 live births). We examined the composite outcomes 'any severe birth trauma' and 'obstetric trauma', as well as each individual types of trauma. The Cochran-Armitage test for trend was used to assess temporal trends in risk factors (confounders) potentially associated with birth and obstetric trauma. These trends were also quantified by rate ratio (RR) and 95\% CIs comparing the most recent years to the earliest years (2011-2013 vs 2004-2006).

Logistic regression was used to estimate the unadjusted ORs, adjusted ORs (AOR) and 95\% CI for severe birth trauma to infant and for obstetric trauma to mother. Temporal trend was expressed as the change in the odds of trauma with each successive calendar year (continuous variable). Adjustment was made for mode of delivery, maternal and infant characteristics and pregnancy risk factors including: race (African-American, Hispanic, Native American and other vs non-Hispanic white), maternal age ( $<25, \geq 35$ years vs $25-34$ years), marital status (single/widowed/separated vs married/common law), 
BMI (underweight $<18.5 \mathrm{~kg} / \mathrm{m}^{2}$, overweight $20-29.9 \mathrm{~kg}$ / $\mathrm{m}^{2}$ and obese $\geq 30 \mathrm{~kg} / \mathrm{m}^{2}$ vs normal $18.5-24.9 \mathrm{~kg} / \mathrm{m}^{2}$ ), smoking during pregnancy, parity (nullipara, grand multipara with $\geq 4$ births vs para 1-3), assisted conception, maternal education (less than high school vs high school or more), maternal morbidity (chronic hypertension and gestational hypertension, chronic diabetes mellitus and gestational diabetes), premature rupture of membranes (PROMs; >12hours), prolonged labour, precipitous labour ( $<3$ hours), obstructed labour or cephalopelvic disproportion, labour induction, previous caesarean delivery, infant birth weight ( $\geq 4000 \mathrm{~g}$ vs $<4000 \mathrm{~g}$ ), preterm birth $(<37$ weeks' gestation) and infant's sex (male vs female). Information on diagnosis of obstructed labour and cephalopelvic disproportion (including diagnosis of shoulder dystocia) was obtained from maternal hospitalisation files. The ICD-9-CM codes for cephalo-pelvic disproportion and obstructed labour were ' $653 .^{\wedge} \wedge^{\prime}$ ' and ' $660 .^{\wedge} \wedge$ ', respectively. The same set of covariates (except for the mode of delivery) was used in logistic regression analyses stratified by mode of delivery. Covariates such as prolonged labour, precipitous labour ( $<3$ hours $)$ and obstructed labour/cephalopelvic disproportion were not used in regression analyses restricted to women with caesarean delivery without labour. All covariates were selected a priori as known risk factors for adverse birth outcomes and birth trauma. Backward stepwise selection process was used to derive final regression models. Maternal obstetric trauma was examined in the regression analysis stratified by mode of delivery only for spontaneous vaginal delivery, forceps and vacuum delivery.

\section{Sensitivity analyses}

Two sensitivity analyses were performed. First, we examined temporal trend in sequential instrumental delivery (using both, vacuum and forceps) and temporal trend in failed instrumental vaginal delivery (ie, delivery by caesarean after a failed attempt to deliver vaginally by vacuum or forceps). Rates of birth trauma were examined in both of these groups and also in women with caesarean delivery with labour after exclusion of failed instrumental vaginal delivery. The second sensitivity analysis was performed to examine trends in deliveries by mid/low-cavity forceps, which has a higher risk of trauma as compared with outlet forceps. ${ }^{26}{ }^{27}$ Adjustment for such forceps thus provided additional insight into temporal changes in birth trauma and obstetric trauma in forceps delivery.

All analyses were performed on publicly accessible deidentified data. Analyses were carried out using SAS V.9.3. Missing values for BMI $(9.27 \%)$ were addressed with multiple imputation (proc MI) using Markov Chain Monte Carlo methods. Other missing values $(<3 \%$ for other covariates) were excluded from multivariable analyses.

\section{RESULTS}

Overall, 871649 mothers gave birth in Washington State between January 2004 and December 2013. After exclusions, the study population consisted of 732818 mothers (online supplementary appendix figure 1). Most infants were born by spontaneous vaginal delivery $(68.29 \%)$ in 2004; this proportion increased slightly to $68.98 \%$ in 2013. The rate of caesarean delivery increased during the study period from $24.76 \%$ to $26.24 \%$, and caesarean with labour decreased from $9.96 \%$ to $8.70 \%$, while caesarean without labour increased from $14.80 \%$ to $17.55 \%$. The rates of forceps delivery declined from $0.90 \%$ to $0.65 \%$, and the rates of vacuum delivery declined from $6.06 \%$ to $4.12 \%$, respectively (figure 1 ).

The rate of neonatal birth trauma declined by $14.12 \%$, from 5.27 per 1000 live births in 2004 to 4.52 in 2013 (P

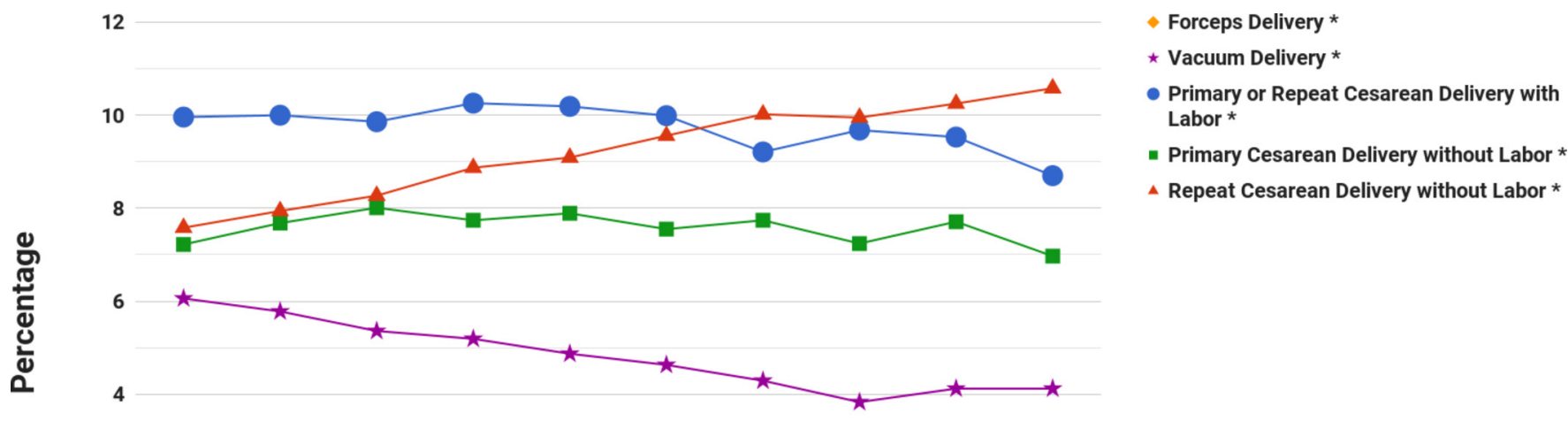

2

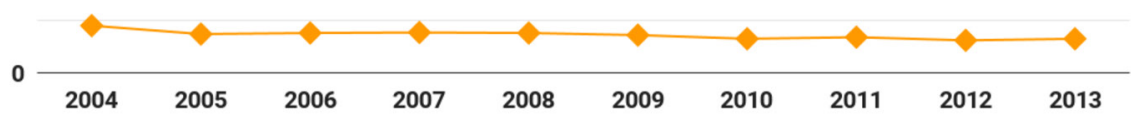

Birth Year

Figure 1 Temporal trends in mode of delivery in singleton infants, Washington State, USA, 2004-2013. 
60

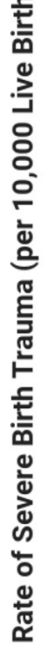

50

40
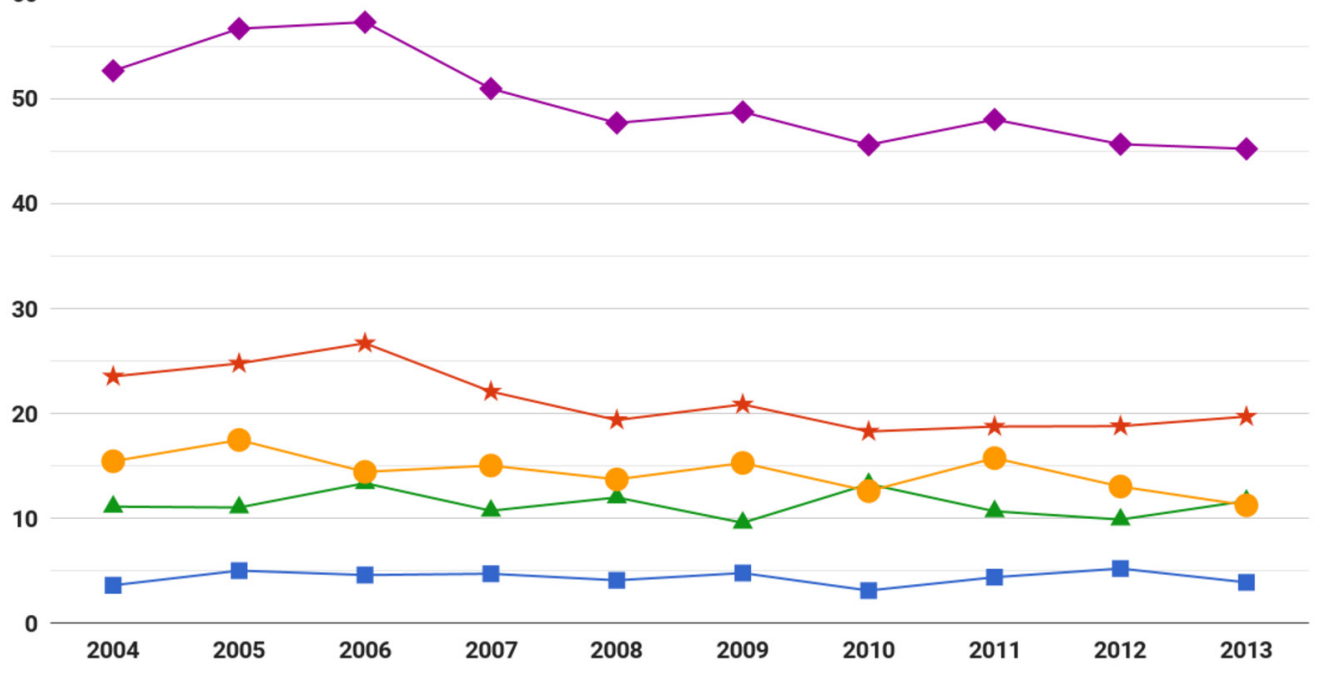

- Any Severe Birth Trauma *

- Brain Injury

$\star$ Fractures *

$\triangle$ Nerve Injury

- Other Severe Birth Trauma *

Birth Year

Figure 2 Temporal trends in severe birth trauma among singleton infants, Washington State, USA, 2004-2013.

for trend $<0.001$, figure 2$)$, the overall risk of any severe birth trauma declined on average by $2 \%$ per year (OR $0.98,95 \%$ CI 0.96 to 0.99$)$. The incidence of birth trauma varied largely by mode of delivery; the average rate of birth trauma was 4.74 per 1000 live births among infants born by spontaneous vaginal delivery, which was lower than the rates among infants born by forceps (25.48 per 1000) and vacuum delivery (14.22 per 1000). Birth trauma rates were substantially lower for all caesarean delivery categories: primary (3.26 per 1000) and repeat (1.85 per 1000) caesarean deliveries without labour as well as primary (4.99 per 1000) and repeat caesarean (3.71 per 1000) with labour. The latter two rates were combined into one category for further analysis (4.89 per 1000 caesarean deliveries with labour), as both had similar rates of birth trauma $(\mathrm{P}=0.284)$. This rate was significantly higher compared with the overall rate of birth trauma following caesarean delivery without labour (2.48 per $1000 ; \mathrm{P}<0.001)$. The majority of infants with birth trauma had only one type of trauma $(97.18 \%)$. Neonatal mortality among infants with birth trauma was two times higher as compared with other infants (4.11 vs 1.97 per 1000 infants; RR 2.08, 95\% CI 1.25 to 3.46). Most neonatal deaths $(75 \%)$ occurred among infants with brain injury.

Unadjusted analysis showed a significant temporal decline in the rates of fractures (from 2.35 to per 1000 live births in 2004 to 1.97 per 1000 live births in 2013, $\mathrm{P}<0.001$ ), and other birth trauma (from 1.54 to 1.12 per 1000 live births, $\mathrm{P}=0.009$; figure 2 ). This decline was seen only in infants delivered by spontaneous vaginal delivery (online supplementary appendix figure 2) for the trauma subcategories of fractures (from 2.83 to 2.19 per 1000 births; $\mathrm{P}<0.001$ ) and other severe birth trauma (from 1.10 to 0.56 per 1000 births; $\mathrm{P}=0.007$ ). In contrast, a statistically significant upward trends was observed in the rate of nerve injury among infants delivered by forceps: from
3.53 per 1000 live births in 2004-2006 to 7.77 per 1000 live births in 2011-2013 ( $\mathrm{P}=0.044)$.

Overall, the rate of maternal obstetric trauma declined from 7.52 in 2004 to 4.09 per 100 live births in 2013 $(\mathrm{P}<0.001)$. Among women with vaginal delivery, the decline was from $9.67 \%$ to $5.22 \%(\mathrm{P}<0.001)$. While the rate of severe perineal lacerations declined from 4.91 to 3.16 per 100 vaginal deliveries $(\mathrm{P}<0.001)$, cervical/high vaginal lacerations remained stable between $1.63 \%$ in 2004 and $1.58 \%$ in 2013 ( $\mathrm{P}=0.458$; online supplementary appendix figure 3). These trends were observed among women with spontaneous vaginal delivery, with forceps and with vacuum delivery (online supplementary appendix figure 3 ).

Significant temporal trends were observed for the majority of maternal and infant risk factors for birth trauma (table 1), except for infant's sex, preterm birth (<34 weeks) and precipitous labour. A noticeable decline was seen in the proportion of births to mothers aged less than 30 years, Hispanic and Native American mothers, mothers with low education (less than high school), mothers who smoked during pregnancy and grand multipara. Temporal declines also occurred in the rates of labour induction, preterm birth ( $<37$ weeks), obstructed labour and cephalopelvic disproportion and birth weight $\geq 4000 \mathrm{~g}$. In contrast, a sizeable increase was observed in the proportion of African-American mothers, mothers with assisted conception, previous caesarean delivery, PROM and prolonged labour. Rates of maternal morbidity, including diabetes mellitus, gestational diabetes, chronic hypertension and hypertension during pregnancy increased between 2004 and 2013.

Regression analyses examining neonatal birth trauma for all deliveries showed that only the trend in the risk of fracture was statically significant before and after adjustment for other covariates (AOR 0.97; 95\% CI 0.95 to 0.99 ; table 2). When stratified by mode of delivery, adjustment 
Table 1 Temporal trends in maternal demographic characteristics and risk factors for birth trauma among singleton infants, Washington State, USA, 2004-2013

\begin{tabular}{|c|c|c|c|c|c|}
\hline \multirow[b]{3}{*}{ Maternal and infant characteristics } & \multicolumn{3}{|l|}{ Birth year } & \multirow{3}{*}{ P value* } & \multirow[b]{2}{*}{$\begin{array}{l}\text { Rate ratio } \\
(95 \% \mathrm{Cl}) \dagger\end{array}$} \\
\hline & $\begin{array}{l}2004-2006 \\
(n=213270)\end{array}$ & $\begin{array}{l}2007-2010 \\
(n=301508)\end{array}$ & $\begin{array}{l}2011-2013 \\
(n=218040)\end{array}$ & & \\
\hline & n (\%) & n (\%) & n (\%) & & \\
\hline \multicolumn{6}{|l|}{ Maternal age (years) } \\
\hline $15-19$ & $17844(8.4)$ & $24380(8.1)$ & $13313(6.1)$ & $<0.001$ & 0.73 (0.71 to 0.75$)$ \\
\hline $20-29$ & 111509 (52.3) & $157445(52.2)$ & $109527(50.2)$ & $<0.001$ & 0.96 (0.96 to 0.97$)$ \\
\hline $30-39$ & $77941(36.6)$ & $111085(36.8)$ & $88445(40.6)$ & $<0.001$ & $1.11(1.10$ to 1.12$)$ \\
\hline$\geq 40$ & $5976(2.8)$ & $8598(2.9)$ & $6755(3.1)$ & $<0.001$ & $1.11(1.07$ to 1.14$)$ \\
\hline \multicolumn{6}{|l|}{ Race } \\
\hline Non-Hispanic white & $153872(72.4)$ & $213846(71.1)$ & $155618(71.6)$ & $<0.001$ & 0.99 (0.99 to 0.99$)$ \\
\hline African-American & $7775(3.7)$ & $12201(4.1)$ & $9699(4.5)$ & $<0.001$ & 1.22 (1.19 to 1.26$)$ \\
\hline Native American & $4445(2.1)$ & $6123(2.0)$ & $4320(2.0)$ & 0.006 & 0.95 (0.91 to 0.99$)$ \\
\hline Hispanic & $25871(12.2)$ & $37531(12.5)$ & $23387(10.8)$ & $<0.001$ & $0.88(0.87$ to 0.90$)$ \\
\hline Other & $20649(9.7)$ & $31131(10.3)$ & $24324(11.2)$ & $<0.001$ & 1.15 (1.13 to 1.17$)$ \\
\hline $\begin{array}{l}\text { Maternal education } \\
\text { (<high school) }\end{array}$ & $9800(4.6)$ & $11318(3.7)$ & $6032(2.8)$ & $<0.001$ & 0.60 (0.58 to 0.62$)$ \\
\hline Smoking during pregnancy & $20834(9.9)$ & $29206(9.8)$ & $19635(9.0)$ & $<0.001$ & 0.91 (0.89 to 0.93$)$ \\
\hline Not married & $67109(31.6)$ & $104035(34.6)$ & 75055 (34.5) & $<0.001$ & $1.09(1.08$ to 1.10$)$ \\
\hline \multicolumn{6}{|l|}{ Parity } \\
\hline Nullipara & $85407(40.0)$ & $124799(41.4)$ & $88428(40.6)$ & 0.010 & 1.01 (1.01 to 1.02$)$ \\
\hline Para 1-3 & $110757(51.9)$ & $159444(52.9)$ & $117743(54.0)$ & $<0.001$ & $1.04(1.03$ to 1.05$)$ \\
\hline $\begin{array}{l}\text { Grand multipara } \\
\text { ( } \geq 4 \text { births) }\end{array}$ & $17106(8.0)$ & $17265(5.7)$ & $11869(5.4)$ & $<0.001$ & 0.68 (0.66 to 0.69$)$ \\
\hline \multicolumn{6}{|l|}{ Body mass index $\left(\mathrm{kg} / \mathrm{m}^{2}\right)$} \\
\hline Underweight $(<18.5)$ & $6240(2.9)$ & $8332(2.8)$ & $6230(2.9)$ & 0.045 & 0.98 (0.94 to 1.00$)$ \\
\hline Normal (18.5 to 24.9$)$ & $89369(41.9)$ & $131590(43.6)$ & $94093(43.1)$ & $<0.001$ & 1.03 (1.02 to 1.04$)$ \\
\hline Overweight (25 to 29.9 ) & $46074(21.6)$ & $72295(24.0)$ & $53849(24.7)$ & $<0.001$ & 1.14 (1.13 to 1.16$)$ \\
\hline Obese $(\geq 30)$ & $39752(18.6)$ & $65239(21.6)$ & $51806(23.8)$ & $<0.001$ & $1.27(1.26$ to 1.29$)$ \\
\hline Missing & $31842(14.9)$ & $24052(8.0)$ & $12062(5.5)$ & $<0.001$ & \\
\hline Assisted conception & $1470(0.7)$ & $2702(0.90)$ & $2249(1.0)$ & $<0.001$ & 1.47 (1.38 to 1.57$)$ \\
\hline $\begin{array}{l}\text { Diabetes mellitus } \\
\text { (types } 1 \text { and 2) }\end{array}$ & $1578(0.7)$ & $2591(0.9)$ & $2151(1.0)$ & $<0.001$ & 1.33 (1.25 to 1.42$)$ \\
\hline Gestational diabetes & $12255(5.75)$ & $19160(6.3)$ & $16382(7.5)$ & $<0.001$ & 1.31 (1.28 to 1.34$)$ \\
\hline Chronic hypertension & $2489(1.2)$ & $3783(1.3)$ & $2815(1.3)$ & $<0.001$ & 1.09 (1.03 to 1.15$)$ \\
\hline Hypertension in pregnancy & $10857(5.1)$ & $15304(5.1)$ & $12010(5.5)$ & $<0.001$ & $1.08(1.06$ to 1.11$)$ \\
\hline Infant sex (male) & $109744(51.5)$ & $154777(51.3)$ & $112326(51.5)$ & 0.846 & 1.00 (1.00 to 1.01$)$ \\
\hline \multicolumn{6}{|l|}{ Preterm birth } \\
\hline$<34$ weeks & $3042(1.4)$ & $4372(1.4)$ & $3255(1.5)$ & 0.104 & 1.05 (1.00 to 1.10$)$ \\
\hline$<37$ weeks & $15006(7.0)$ & $20067(6.7)$ & $14265(6.5)$ & $<0.001$ & 0.93 (0.91 to 0.95$)$ \\
\hline \multicolumn{6}{|l|}{ Birth weight (g) } \\
\hline$<2500$ & $9414(4.4)$ & $13448(4.5)$ & $10186(4.7)$ & $<0.001$ & 1.06 (1.03 to 1.09$)$ \\
\hline 2500-2999 & $29718(14.0)$ & $43033(14.3)$ & $31990(14.7)$ & $<0.001$ & 1.05 (1.04 to 1.07$)$ \\
\hline 3000-3999 & $149045(70.1)$ & 211901 (70.3) & $151953(69.7)$ & 0.002 & $1.00(0.99$ to 1.00$)$ \\
\hline $4000-4499$ & $20754(9.8)$ & $28051(9.3)$ & $20094(9.2)$ & $<0.001$ & 0.95 (0.93 to 0.96$)$ \\
\hline$\geq 4500$ & $3731(1.75)$ & $4819(1.6)$ & $3640(1.7)$ & 0.005 & $0.95(0.91$ to 1.00$)$ \\
\hline
\end{tabular}


Table 1 Continued

\begin{tabular}{|c|c|c|c|c|c|}
\hline \multirow[b]{3}{*}{ Maternal and infant characteristics } & \multicolumn{3}{|l|}{ Birth year } & \multirow{3}{*}{ P value* } & \multirow[b]{2}{*}{$\begin{array}{l}\text { Rate ratio } \\
(95 \% \mathrm{Cl}) \dagger\end{array}$} \\
\hline & $\begin{array}{l}2004-2006 \\
(n=213270)\end{array}$ & $\begin{array}{l}2007-2010 \\
(n=301508)\end{array}$ & $\begin{array}{l}2011-2013 \\
(n=218040)\end{array}$ & & \\
\hline & n (\%) & n (\%) & n (\%) & & \\
\hline \multicolumn{6}{|l|}{ Caesarean delivery } \\
\hline Primary with labour & $19965(9.4)$ & $27960(9.3)$ & $18323(8.4)$ & $<0.001$ & 0.90 (0.88 to 0.92$)$ \\
\hline Primary no labour & $16310(7.6)$ & $23314(7.7)$ & $15930(7.3)$ & $<0.001$ & 0.96 (0.94 to 0.98$)$ \\
\hline Repeat with labour & $1227(0.6)$ & $1939(0.6)$ & $1961(0.9)$ & $<0.001$ & 1.56 (1.46 to 1.68$)$ \\
\hline Repeat no labour & $16931(7.9)$ & $28281(9.4)$ & $22366(10.3)$ & $<0.001$ & 1.29 (1.27 to 1.32$)$ \\
\hline \multicolumn{6}{|l|}{ Vaginal delivery } \\
\hline Spontaneous & $144931(68.0)$ & $203513(67.5)$ & $149270(68.5)$ & $<0.001$ & 1.01 (1.00 to 1.01$)$ \\
\hline Forceps & $1698(0.8)$ & $2185(0.7)$ & $1416(0.6)$ & $<0.001$ & 0.82 (0.76 to 0.88$)$ \\
\hline Vacuum & $12208(5.7)$ & $14316(4.7)$ & $8774(4.0)$ & $<0.001$ & 0.70 (0.68 to 0.72$)$ \\
\hline \multicolumn{6}{|l|}{ Previous caesarean delivery } \\
\hline One prior delivery & $16198(7.6)$ & $25871(8.6)$ & $21049(9.6)$ & $<0.001$ & 1.27 (1.25 to 1.30$)$ \\
\hline Two or more & $4518(2.1)$ & $8821(2.9)$ & 8069 (3.7) & $<0.001$ & 1.75 (1.68 to 1.81$)$ \\
\hline Labour induction & $50584(24.2)$ & $69022(23.1)$ & $48530(22.3)$ & $<0.001$ & 0.92 (0.91 to 0.93 ) \\
\hline PROM (>12 hours) & $8435(4.1)$ & $16232(5.5)$ & $13246(6.1)$ & $<0.001$ & 1.50 (1.46 to 1.54$)$ \\
\hline Precipitous labour (<3 hours) & $6323(3.1)$ & 9595 (3.2) & $6486(3.0)$ & 0.475 & 0.98 (0.95 to 1.01$)$ \\
\hline Prolonged labour & 3206 (1.5) & $7759(2.6)$ & $5691(2.6)$ & $<0.001$ & 1.69 (1.62 to 1.77$)$ \\
\hline Cephalopelvic disproportion & $6669(3.1)$ & $7873(2.6)$ & $4374(2.0)$ & $<0.001$ & 0.64 (0.62 to 0.67$)$ \\
\hline Obstructed labour & $16256(7.6)$ & $21224(7.0)$ & $13524(6.2)$ & $<0.001$ & 0.81 (0.80 to 0.83$)$ \\
\hline
\end{tabular}

Breech delivery excluded.

${ }^{*}$ Cochran-Armitage test for trend.

†Rate ratio comparing periods 2011-2013 versus 2004-2006.

PROM, premature rupture of membranes.

for potential confounders did not change the downward temporal trend in fractures and other birth trauma among infants delivered by spontaneous vaginal delivery (table 3 ); the rate of fractures declined on average by $5 \%$ per year (AOR $0.95,95 \%$ CI 0.94 to 0.97 ), while the risk of other birth trauma declined on average by $4 \%$ per year (AOR $0.96,95 \%$ CI 0.93 to 0.99 ). The unadjusted increase in the risk of nerve injury among infants born by forceps

Table 2 Unadjusted and adjusted ORs expressing the change per year in the risk of birth trauma among singleton infants, Washington State, USA, 2004-2013

\begin{tabular}{|c|c|c|c|}
\hline Severe birth trauma & $\begin{array}{l}\text { OR } \\
(95 \% \mathrm{Cl})\end{array}$ & $\begin{array}{l}\text { AOR* }^{\star} \\
(95 \% \mathrm{Cl})\end{array}$ & $\begin{array}{l}\text { AOR }^{\star \star} \\
(95 \% \mathrm{Cl})\end{array}$ \\
\hline Brain injury & $\begin{array}{l}1.00 \\
(0.96 \text { to } 1.04)\end{array}$ & $\begin{array}{l}1.01 \\
(0.98 \text { to } 1.05)\end{array}$ & $\begin{array}{l}1.02 \\
(0.98 \text { to } 1.06)\end{array}$ \\
\hline Fractures & $\begin{array}{l}0.96 \\
(0.95 \text { to } 0.98)\end{array}$ & $\begin{array}{l}0.97 \\
(0.95 \text { to } 0.99)\end{array}$ & $\begin{array}{l}0.97 \\
(0.95 \text { to } 0.99)\end{array}$ \\
\hline Nerve injury & $\begin{array}{l}0.99 \\
(0.97 \text { to } 1.02)\end{array}$ & $\begin{array}{l}1.00 \\
(0.98 \text { to } 1.03)\end{array}$ & $\begin{array}{l}1.00 \\
(0.98 \text { to } 1.03)\end{array}$ \\
\hline Any severe birth trauma & $\begin{array}{l}0.98 \\
\text { (0.96 to } 0.99)\end{array}$ & $\begin{array}{l}0.98 \\
(0.97 \text { to } 0.99)\end{array}$ & $\begin{array}{l}0.98 \\
(0.972 \text { to } 0.995)\end{array}$ \\
\hline
\end{tabular}

Breech delivery was excluded.

${ }^{\star}$ Adjusted for temporal changes in mode of delivery.

†Adjusted for temporal changes in mode of delivery and other risk factors (parity, body mass index, maternal age, maternal education, race, marital status, assisted conception, hypertension, diabetes mellitus, gestational diabetes, smoking during pregnancy, birth weight, preterm birth, PROM (>12 hours), precipitous labour, prolonged labour, cephalopelvic disproportion, obstructed labour and fetal sex).

AOR, adjusted OR; PROM, premature rupture of membranes. 


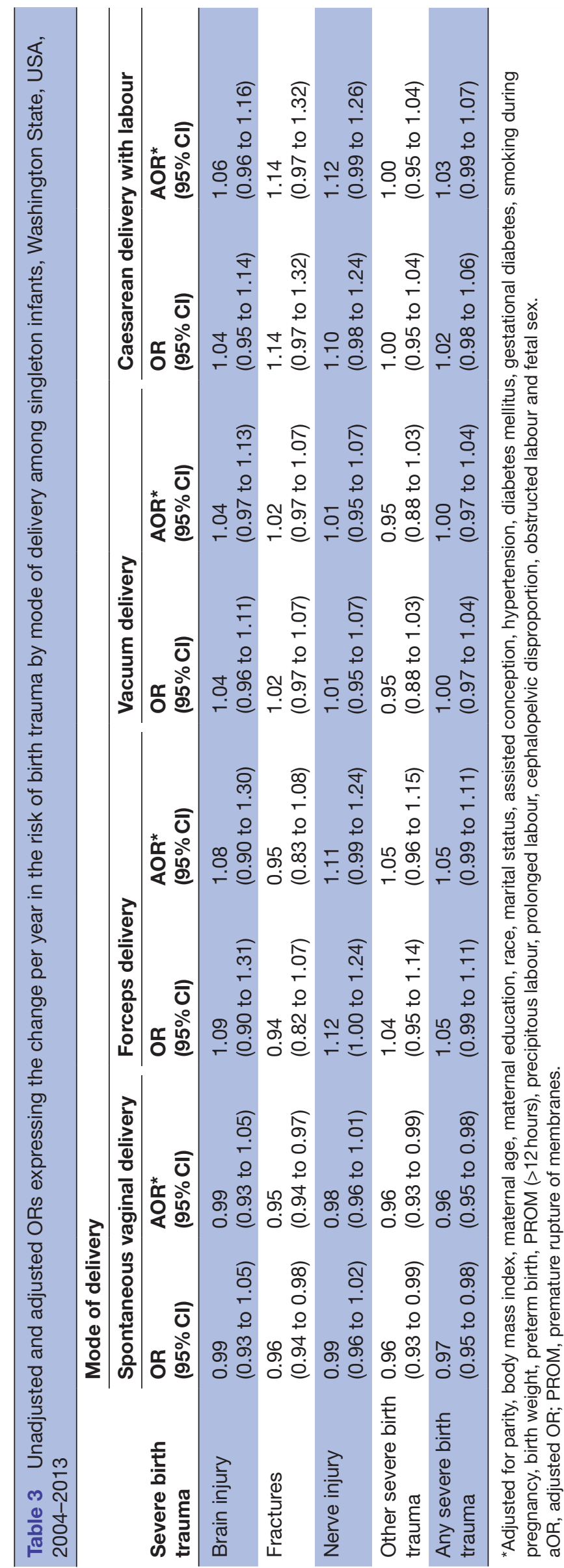

delivery (OR 1.12, 95\% CI 1.00 to 1.24 ) attenuated and was no longer significant after adjustment for temporal changes in other risk factors (AOR 1.11, 95\% CI 0.99 to 1.24).

Regression analyses of maternal obstetric trauma showed that the risk of severe perineal lacerations declined over time, even after adjustment for mode of delivery and other risk factors (table 4 ). The risk of cervical/high vaginal lacerations remained unchanged. The temporal decline in severe perineal laceration in forceps delivery was not significant after adjustment for other covariates (online supplementary appendix table 2 ).

\section{Sensitivity analyses}

Sensitivity analyses showed a temporal decline in the rates of sequential instrumental vaginal delivery (from $0.11 \%$ in 2004-2006 to $0.04 \%$ in $2011-2013$; RR 0.39 ; $95 \%$ CI 0.30 to 0.49 ); and a small temporal decline in the rates of failed instrumental vaginal delivery resulting in caesarean section (from $0.35 \%$ in $2004-2006$ to $0.30 \%$ in $2011-$ 2013). The rate of birth trauma remained unchanged in both groups (the average rates were 40.23 and 17.38 per 1000 live births, respectively). The rate of birth trauma did not change significantly among women with caesarean delivery with labour without failed instrumental delivery; the average rate was 4.47 per 1000 live births. Additional analyses showed that the proportion of mid/low-cavity forceps among women with forceps delivery increased from $4.83 \%$ in 2004 to $6.17 \%$ in 2013 ; this trend was not statistically significant $(\mathrm{P}=0.086)$. The overall rate of mid/ low-cavity forceps remained relatively unchanged among women with vaginal delivery (0.52 in 2004-2006 and 0.55 per 1000 vaginal deliveries in 2011-2013). Adjustment for mid/low-cavity forceps did not change the results for infants and women with forceps delivery.

\section{DISCUSSION}

Monitoring temporal trends in major adverse health outcomes in childbearing women and their infants is important for identification of potential problems and areas for improvement in quality of maternal and infant care. Our results show a significant decline in the rate of severe birth trauma in Washington State, USA, between 2004 and 2013. This trend remained unchanged after adjustment for a temporal increase in caesarean delivery and concurrent decrease in instrumental vaginal delivery as well as after adjustment for other temporal changes in risk factors for birth trauma. Detailed analyses showed that the significant declines occurred only in the rates of fractures and other severe birth trauma among infants delivered by spontaneous vaginal delivery, whereas the rates of brain injury and nerve injury remained unchanged. The rates of severe perineal lacerations declined among women with spontaneous vaginal delivery and vacuum delivery.

Most studies have focused on the association of birth trauma with mode of delivery showing an increased risk 
Table 4 Unadjusted and adjusted ORs expressing the change per year in the risk of maternal obstetric trauma among singleton infants, Washington State, USA, 2004-2013

\begin{tabular}{llll}
\hline Obstetric trauma & $\begin{array}{l}\text { OR } \\
\mathbf{9 5 \%} \mathbf{C l})\end{array}$ & $\begin{array}{l}\text { AOR } \\
\left.\mathbf{( 9 5 \% ~}^{*} \mathbf{C l}\right)\end{array}$ & $\begin{array}{l}\text { AOR† } \\
\mathbf{( 9 5 \%} \mathbf{C I})\end{array}$ \\
\hline $\begin{array}{l}\text { Severe perineal lacerations } \\
\text { Cervical/high vaginal }\end{array}$ & $0.95(0.95$ to 0.96$)$ & $0.96(0.96$ to 0.97$)$ & $0.96(0.95$ to 0.96$)$ \\
lacerations & $0.99(0.99$ to 1.00$)$ & $1.00(0.99$ to 1.01$)$ & $1.00(0.99$ to 1.00$)$ \\
Any severe lacerations & $0.91(0.91$ to 0.92$)$ & $0.92(0.92$ to 0.92$)$ & 0.91 (0.91 to 0.92) \\
\hline
\end{tabular}

Breech delivery was excluded.

${ }^{*}$ Adjusted for temporal changes in mode of delivery.

†Adjusted for temporal changes in mode of delivery and other risk factors (parity, body mass index, maternal age, maternal education, race, marital status, assisted conception, hypertension, diabetes mellitus, gestational diabetes, smoking during pregnancy, birth weight, preterm birth, PROM (>12 hours), precipitous labour, prolonged labour, cephalopelvic disproportion, obstructed labour and fetal sex). aOR, adjusted OR; PROM, premature rupture of membranes.

of birth trauma among infants delivered by instrumental vaginal delivery as compared with vaginal or caesarean delivery. ${ }^{3-5} 26-30$ For example, Towner et a $\vec{l}$ reported the incidence rate of intracranial haemorrhage of 0.43 per 1000 infants born by spontaneous vaginal delivery in contrast with 1.16 and 1.57 per 1000 infants delivered by vacuum and forceps, respectively. Our study confirmed that the rate of instrumental vaginal delivery declined over the last 10 years while the rate of caesarean delivery increased, mainly due to increases in the rate of repeat caesarean delivery without labour. In agreement with our hypothesis, the magnitude of decline in the overall rate of birth trauma was slightly attenuated after adjustment for mode of delivery; however, the decline in the rate of birth trauma remained significant after adjustment for temporal changes in other risk factors.

The reasons for the decline in fractures and other birth trauma among spontaneous vaginal deliveries are unclear. The majority of fractures were fractures of the clavicle, which some obstetricians regard as an unavoidable event. ${ }^{31}$ We did not find any evidence of the effect of temporal changes in major risk factors for fractures, including large birth weight, prolonged labour, precipitous labour, high BMI and obstructed labour or cephalopelvic disproportion (including shoulder dystocia), ${ }^{32-35}$ as adjustment for these factors did not change the trends substantially. Clinical recognition of fractured clavicle may not be obvious, and some fractures may be identified only after discharge. ${ }^{36} 37$ Thus, changes in clinical vigilance with respect to clavicular fractures that were unsuspected during spontaneous vaginal delivery may have influenced the temporal trends. Another possible explanation is improved selection of low-risk childbearing women for vaginal delivery, resulting in a lower proportion of complicated vaginal delivery and less need for vacuum and forceps. This explanation is only indirectly supported in our study by a concomitant increase in repeat caesarean delivery without labour and therefore remains speculative, as our study was not designed to examine such phenomena beyond the changes in risk factors that we adjusted for in multivariable analyses. The decline in the rate of birth trauma could also be attributed to improved quality of care. Rate of birth trauma has been recommended as one of the indicators for quality of prenatal care. ${ }^{38-41}$ However, this notion has recently been contended due to several limitations, including the lack of a consistent definition, uncertainty about preventability of some injuries and variations in clinical recognition at birth. ${ }^{38} 42$ Nevertheless, the decline in the rate of severe perineal lacerations in our study, which was not explained by temporal changes in underlying population risk factors, also point to improved quality of care (if we assume that the quality of obstetric trauma reporting did not decline over time).

In contrast to our findings, some previous studies showed increased rates of obstetric trauma in Sweden from $1.7 \%$ in 1990 to $4.2 \%$ in 2004, ${ }^{11}$ and in England from $1.8 \%$ in 2000 to $5.9 \%$ in $2012,{ }^{43}$ that were not explained by temporal changes in risk factors. These studies concluded that the most likely reason for an increase in obstetric trauma was an improvement in recognition of lacerations. ${ }^{111243}$

Our study has several strengths. We used large population databases with detailed information on maternal and pregnancy risk factors, labour and delivery characteristics and infant outcomes. The information on birth trauma was collected consistently over the study period using ICD-9-CM codes. The linkage between hospitalisation data and birth certificates has been shown to improve overall data accuracy. ${ }^{44}{ }^{45}$ Previous validation studies of the linked datase ${ }^{445}$ showed that the positive and negative predictive value was above $80 \%$ and $98 \%$, respectively, for majority of labour and delivery information in birth certificates and in CHARS as compared with a gold standard of manually abstracted and reabstracted data from medical charts. ${ }^{44}$ We had detailed information on mode of delivery and were able to adjust for the majority of other known risk factors for birth trauma, including BMI (with approximately $9 \%$ of values imputed).

Our study has several limitations. First, statistical power to detect temporal trends for some specific injuries may have been limited when examined by mode of delivery and adjusted for potential confounders. Second, the exact degree of severity of 'other birth trauma' was 
not possible to ascertain from the ICD-9-CM code. This condition includes severe injury (eye damage, traumatic glaucoma, haematoma/rupture of liver and spleen and injury to adrenal gland) and potentially less severe injury (such as scalpel wound laceration), haematoma of vulva and testes and haematoma of sternomastoid. We therefore reported on specific categories of birth trauma that are more homogenous in terms of severity. Third, the proportion of missing values for BMI declined during the study period. We used multiple imputation to adjust for BMI in the multivariable analysis. Fourth, some errors and omissions in diagnostic coding are inevitable in all large administrative databases. However, these errors would have resulted in non-differential misclassification, potentially resulting in underestimation of temporal trends. Fifth, the linked dataset did not include information on antepartum versus intrapartum stillbirths, thus the analysis did not account for birth trauma resulting in intrapartum stillbirth. Lastly, hypoxic-ischaemic encephalophathy (HIE), which can result from birth trauma, was not included in the analysis of temporal trends. This was due to inconsistencies in the ICD-9-CM coding (ICD-9-CM code for HIE was introduced in 2007) ${ }^{46}$ and clinical definition of HIE over the study period (HIE vs birth asphyxia or other encephalopathy, which can result from other causes including placental abruption, uterine rupture and cord prolapse). ${ }^{47}$

\section{CONCLUSION}

Our study showed a temporal decline in fractures and other birth trauma among infants with spontaneous vaginal delivery in the past 10 years. Although rates of forceps and vacuum delivery declined over time, the rates of birth trauma following such delivery remained unchanged and higher as compared with all other types of delivery. Rate of severe perineal lacerations declined over time in all types of vaginal delivery, suggesting improved obstetric care.

Contributors SL and GMM designed the study, SL and QW performed data analysis and QW and SL wrote the first draft of the manuscript. GMM, JT, SC and KIL helped with the interpretation of the results and critically revised this first draft. All authors approved the final version of the manuscript.

Funding This study was supported by funding from the Canadian Institutes of Health Research (grants APR-126338 and MAH-15445). SL is supported by a Scholar Award from the Michael Smith Foundation for Health Research. GMM is supported by a Vanier Canada Graduate Scholarship. JT is supported by the Investigator Grant Award Program from British Columbia Children's Hospital Research Institute.

Competing interests None declared.

Patient consent Not required.

Ethics approval An exemption from ethics approval was granted by the Department of Social and Health Services, State of Washington.

Provenance and peer review Not commissioned; externally peer reviewed.

Data sharing statement Analyses were based on administrative data collected and maintained by the Department of Health, State of Washington. The availability of the data is restricted. Permission for data access can granted after verification of the research goals by the Department of Social and Health Services, State of Washington.
Open Access This is an Open Access article distributed in accordance with the Creative Commons Attribution Non Commercial (CC BY-NC 4.0) license, which permits others to distribute, remix, adapt, build upon this work non-commercially, and license their derivative works on different terms, provided the original work is properly cited and the use is non-commercial. See: http://creativecommons.org/ licenses/by-nc/4.0/

(c) Article author(s) (or their employer(s) unless otherwise stated in the text of the article) 2018. All rights reserved. No commercial use is permitted unless otherwise expressly granted.

\section{REFERENCES}

1. Parker LA. Part 1: early recognition and treatment of birth trauma: injuries to the head and face. Adv Neonatal Care 2005;5:288-97.

2. Sauber-Schatz EK, Markovic N, Weiss HB, et al. Descriptive epidemiology of birth trauma in the United States in 2003. Paediatr Perinat Epidemiol 2010;24:116-24.

3. Towner D, Castro MA, Eby-Wilkens E, et al. Effect of mode of delivery in nulliparous women on neonatal intracranial injury. $N$ Engl $\mathrm{J}$ Med 1999;341:1709-14.

4. Baskett TF, Allen VM, O'Connell CM, et al. Fetal trauma in term pregnancy. Am J Obstet Gynecol 2007;197:e1-7.

5. Moczygemba CK, Paramsothy P, Meikle S, et al. Route of delivery and neonatal birth trauma. Am J Obstet Gynecol 2010;202:e1-6.

6. Tomashek KM, Crouse CJ, lyasu S, et al. A comparison of morbidity rates attributable to conditions originating in the perinatal period among newborns discharged from United States hospitals, 1989-90 and 1999-2000. Paediatr Perinat Epidemiol 2006;20:24-34.

7. Harkin R, Fitzpatrick M, O'Connell PR, et al. Anal sphincter disruption at vaginal delivery: is recurrence predictable? Eur $J$ Obstet Gynecol Reprod Biol 2003;109:149-52.

8. Hirayama F, Koyanagi A, Mori R, et al. Prevalence and risk factors for third- and fourth-degree perineal lacerations during vaginal delivery: a multi-country study. BJOG 2012;119:340-7.

9. Lowder JL, Burrows LJ, Krohn MA, et al. Risk factors for primary and subsequent anal sphincter lacerations: a comparison of cohorts by parity and prior mode of delivery. Am J Obstet Gynecol 2007;196:e1-5.

10. Lisonkova S, Lavery JA, Cande VA, et al. Temporal trends in obstetric trauma and surgery for pelvic floor disorders: age-period-cohort analysis. Am J Obstet Gynecol 2016;208:e1-12.

11. Laine K, Gissler M, Pirhonen J. Changing incidence of anal sphincter tears in four Nordic countries through the last decades. Eur J Obstet Gynecol Reprod Biol 2009;146:71-5.

12. Laine K, Skjeldestad FE, Sanda B, et al. Prevalence and risk factors for anal incontinence after obstetric anal sphincter rupture. Acta Obstet Gynecol Scand 2011;90:319-24.

13. Macarthur AJ, Macarthur C, Incidence MC. Incidence, severity, and determinants of perineal pain after vaginal delivery: a prospective cohort study. Am J Obstet Gynecol 2004;191:1199-204.

14. Rathfisch G, Dikencik BK, Kizilkaya Beji N, et al. Effects of perineal trauma on postpartum sexual function. J Adv Nurs 2010;66:2640-9.

15. Fenner DE, Genberg B, Brahma P, et al. Fecal and urinary incontinence after vaginal delivery with anal sphincter disruption in an obstetrics unit in the United States. Am J Obstet Gynecol 2003;189:1543-9.

16. Macarthur C, Glazener C, Lancashire R, et al. Faecal incontinence and mode of first and subsequent delivery: a six-year longitudinal study. BJOG 2005;112:1075-82.

17. Sultan AH, Kamm MA, Hudson CN, et al. Third degree obstetric anal sphincter tears: risk factors and outcome of primary repair. BMJ 1994;308:887-91.

18. Gyhagen M, Bullarbo M, Nielsen TF, et al. Faecal incontinence 20 years after one birth: a comparison between vaginal delivery and caesarean section. Int Urogynecol J 2014;25:1411-8.

19. Gyhagen M, Bullarbo M, Nielsen TF, et al. A comparison of the longterm consequences of vaginal delivery versus caesarean section on the prevalence, severity and bothersomeness of urinary incontinence subtypes: a national cohort study in primiparous women. BJOG 2013;120:1548-55.

20. Handa VL, Blomquist JL, Knoepp LR, et al. Pelvic floor disorders $5-10$ years after vaginal or cesarean childbirth. Obstet Gynecol 2011;118:777-84.

21. Haadem K, Ohrlander S, Lingman G. Long-term ailments due to anal sphincter rupture caused by delivery--a hidden problem. Eur $J$ Obstet Gynecol Reprod Biol 1988;27:27-32. 
22. Betrán AP, Ye J, Moller AB, et al. The Increasing Trend in Caesarean Section Rates: Global, Regional and National Estimates: 1990-2014. PLoS One 2016:11:e0148343.

23. Hamilton BE, Martin JA, Osterman MJ, et al. Births: final data for 2014. Natl Vital Stat Rep 2015;64:e51.

24. Public Health Agency of Canada. Perinatal Health Indicators for Canada 2013: a Report of the Canadian Perinatal Surveillance System. Ottawa, 2013. http://publications.gc.ca/site/eng/411563/ publication.html. (accessed Aug 2016).

25. Muraca GM, Sabr Y, Brant R, et al. Temporal and regional variations in operative vaginal delivery in Canada by pelvic station, 2004-2012. J Obstet Gynaecol Can 2016;38:627-35.

26. Ducarme G, Hamel JF, Bouet PE, et al. Maternal and neonatal morbidity after attempted operative vaginal delivery according to fetal head station. Obstet Gynecol 2015;126:521-9.

27. Halscott TL, Reddy UM, Landy HJ, et al. Maternal and neonatal outcomes by attempted mode of operative delivery from a low station in the second stage of labor. Obstet Gynecol 2015;126:1265-72.

28. Walsh CA, Robson M, McAuliffe FM. Mode of delivery at term and adverse neonatal outcomes. Obstet Gynecol 2013;121:122-8.

29. Werner EF, Janevic TM, Illuzzi J, et al. Mode of delivery in nulliparous women and neonatal intracranial injury. Obstet Gynecol 2011;118:1239-46.

30. Murphy DJ, Liebling RE, Verity L, et al. Early maternal and neonatal morbidity associated with operative delivery in second stage of labour: a cohort study. Lancet 2001;358:1203-7.

31. Chez RA, Carlan S, Greenberg SL, et al. Fractured clavicle is an unavoidable event. Am J Obstet Gynecol 1994;171:797-8.

32. Lam MH, Wong GY, Lao TT. Reappraisal of neonatal clavicular fracture. Relationship between infant size and risk factors. J Reprod Med 2002;47:903-8.

33. Dyachenko A, Ciampi A, Fahey J, et al. Prediction of risk for shoulder dystocia with neonatal injury. Am J Obstet Gynecol 2006;195:1544-9.

34. Hankins GD, Clark SM, Munn MB. Cesarean section on request at 39 weeks: impact on shoulder dystocia, fetal trauma, neonatal encephalopathy, and intrauterine fetal demise. Semin Perinatol 2006;30:276-87.

35. Iskender C, Kaymak O, Erkenekli K, et al. Neonatal injury at cephalic vaginal delivery: a retrospective analysis of extent of association with shoulder dystocia. PLoS One 2014;9:e104765.
36. Joseph PR, Rosenfeld W. Clavicular fractures in neonates. Am J Dis Child 1990;144:165-7.

37. Lam MH, Wong GY, Lao TT. Reappraisal of neonatal clavicular fracture: relationship between infant size and neonatal morbidity. Obstet Gynecol 2002;100:115-9.

38. Walker S, Strandjord TP, Benedetti TJ. In search of perinatal quality outcome measures: 1 hospital's in-depth analysis of the Adverse Outcomes Index. Am J Obstet Gynecol 2010;203:e1-7.

39. Forum NQ. NQF). National Voluntary Consensus Standards for Perinatal Care 2008: A Consensus Report. Washington, DC: NQF, 2009. http://app.ihi.org/extranetng/content/fdb3913c-db0f-481f9553-1ee7ed523088/7068fe58-6271-4702-af4f-d9f1d03fa810/ Executive_Summary_for_Perinatal_Report.pdf. (accessed Aug 2016).

40. Mann S, Pratt S, Gluck P, et al. Assessing quality obstetrical care: development of standardized measures. Jt Comm J Qual Patient Saf 2006;32:497-505.

41. Mazza F, Kitchens J, Akin M, et al. The road to zero preventable birth injuries. Jt Comm J Qual Patient Saf 2008;34:201-5.

42. Kumar P, Papile LA, Watterberg K. Are current measures of neonatal birth trauma valid indicators of quality of care? $J$ Perinatol 2015;35:903-6.

43. Gurol-Urganci I, Cromwell DA, Edozien LC, et al. Third- and fourth-degree perineal tears among primiparous women in England between 2000 and 2012: time trends and risk factors. BJOG 2013;120:1516-25.

44. Lydon-Rochelle MT, Holt VL, Nelson JC, et al. Accuracy of reporting maternal in-hospital diagnoses and intrapartum procedures in Washington State linked birth records. Paediatr Perinat Epidemiol 2005;19:460-71.

45. Lydon-Rochelle MT, Holt VL, Cárdenas V, et al. The reporting of preexisting maternal medical conditions and complications of pregnancy on birth certificates and in hospital discharge data. Am J Obstet Gynecol 2005;193:125-34.

46. Center for Disease Control. ICD-9-CM Coordination and Maintenance Committee Meeting Notes. 2006 https://www.cdc.gov/ nchs/data/icd/agendamar06.pdf (accessed 20 Dec 2017).

47. Graham EM, Ruis KA, Hartman AL, et al. A systematic review of the role of intrapartum hypoxia-ischemia in the causation of neonatal encephalopathy. Am J Obstet Gynecol 2008;199:587-95. 